\title{
Synthetic seeds and their role in agriculture: status and progress in sub-Saharan Africa
}

\author{
Phetole Mangena \\ Department of Biodiversity, School of Molecular and Life Sciences, Faculty of Science and Agriculture, University of Limpopo, Private Bag \\ X1106, Sovenga, 0727, Republic of South Africa \\ *Email: Phetole.Mangena@ul.ac.za
}

\section{ARTICLE HISTORY \\ Received: 03 February 2021 \\ Accepted: 03 March 2021}

Available online: 01 July 2021

\section{KEYWORDS}

In vitro regeneration

Legumes

Micropropagation

Somatic embryogenesis

Synthetic seeds

Tissue culture

\section{ABSTRACT}

Dicot seeds are commonly characterised by the rapid loss of moisture, vigour and longevity that cause adverse physiological and biochemical effects. Such changes reduce seed viability, germinability and seedling vigour in most agronomic legume crops. Thus, this paper evaluates the potential role of synthetic seed production as an avenue to achieve genetic variability, avert recalcitrance and fleet seed viability challenges experienced in recalcitrant legume species. Synthetic seeds, also known as synseeds or artificial seeds produced via somatic embryogenesis are crucial for the successful establishment of plants, and serve as an important determinant of plant productivity, especially for crops such as soybean. The potential use of synseeds could serve a fundamental role in ensuring cheap and rapid supply of new genetic resources and seed propagules for both breeders and farmers. This approach will ultimately maximise crop yield and offer a tremendous potential for micropropagation and germplasm preservation of recalcitrant species in sub-Saharan Africa. This review reports on a variety of applications and benefits of plant biotechnology in the African context and highlights important advantages such as genetic uniformity, simplified handling, storage, efficient distribution etc. that could be of immeasurable benefit to the seed value chain in agriculture, particularly for rural communities in these developing countries.

\section{Introduction}

Micropropagation by plant tissue culture is one of the most interesting and promising areas of applied and commercial research in plant biotechnology. This approach presents the opportunity to establish and maintain plant organs (shoots, roots, stems, embryos, flowers etc.) and tissues (cells, callus and protoplasts) under aseptic culture conditions for mass propagation. The system additionally exerts a high degree of culture control over each aspect of in vitro regeneration, especially through the control of environmental culture conditions to accelerate and successfully achieve clonal propagation in many commercially viable and recalcitrant plant species. Among the techniques used to regenerate plants via tissue culture, the use of synthetic seeds (also called synseed or artificial seeds) may serve as a valuable alternative technology for preservation and micropropagation of important agroeconomic legume crops (1). Synthetic seeds contain somatic embryos that are directly encapsulated or are partially dehydrated before encapsulation within artificial seed coats (2). The seeds can then be sown for germination in soils or culture media like traditional seeds, which is also a way of sowing somatic embryos for mass propagation.

Synthetic seeds may be used for clonal propagation to replace traditional practices that include natural seed propagation and seeds derived from artificial hybrids. The technique may also lead to the development of drought tolerant varieties and disease-free or resistant plants. Therefore, this technique can be fast-tracked for commercial applications such as crop improvement and various other strategies for inducing genetic interference. This procedure undoubtedly holds considerable potential for major biotechnological applications that are highly required to counteract seed recalcitrance of many food legume crops grown in Sub-Saharan Africa where unemployment, poverty and hunger are rife. Sub-Saharan African countries import an increasingly high number of agricultural products than most countries and the population still experiences the highest prevalence of undernourishment (3). The agricultural sector's productivity in this region still lags far behind other regions. This is primarily due to 
the lack of innovation in agriculture and limited adoption of improved seed varieties. Modernisation of agriculture by the inclusion of biotechnological approaches and modern breeding tools, as well as the adoption of genetically improved varieties remain a major priority, and a prerequisite for achieving increased crop yield and quality.

Failure of implementation of agricultural policies, water scarcity, lack of significant financial investment and creative innovations in agriculture are some of the major persistent problems that are experienced in this region (4). However, production of high quality seeds and other propagating materials will positively influence potential yield, distribution, processing and consumption of many recalcitrant legume crops. Legumes such as groundnut, common bean (Phaseolus vulgaris L.), pea (Pisum sativum L.), lentil (Lens culinaris), mung bean (Vigna radiata L.), faba bean (Vicia faba L), cow pea (Vigna unguiculata L.), pigeon pea (Cajanus cajan L.) and soybean (Glycine max L.) belonging to the Fabaceae family play a critical role in human nutrition (5-11). Interest in these legumes as functional food and chemical ingredients immensely grew in the past decades. This prompted many studies focussing on their nutritional composition, agronomy and medicinal value $(5,9)$. Furthermore, the global significance of these crops emanated from the presence of relatively high amounts of quality proteins, carbohydrates, unsaturated fats, starch, phytochemicals and a high content of mineral elements (12).

Legume seeds contain lesser amounts of saturated fats and have no cholesterol. The seeds contain high amounts of oil comparable to that of cotton seed (Gossypium hirsutum L.) and rape/canola seeds (Brassica napus) (13). It is, therefore, due to the above-mentioned benefits that, legumes showing recalcitrance to germination or genetic improvement be tested via direct or indirect somatic embryogenesis for micropropagation. Important factors that determine the application of tissue culture based protocols include the level of vigour/viability of seeds and explants, as well as the inefficiencies of in vitro regeneration protocols, when cultures are established under nutrient improved medium. This situation demands scientists to explore the potential role of synthetic seeds on clonal propagation of important recalcitrant legume seed crops to complement conventional seed propagation. The main objectives of this paper were to analyse the status of biotechnology in sub-Saharan Africa, review the role of plant tissue culture and its specialised techniques such as synthetic seed technology in agriculture, and strengthen the debate around the use of mass propagation via synthetic seeds to reach commercial applications in this region.

\section{Recalcitrant Seeds of Legume Species}

Almost all grain legume crops remain well known for their highest levels of recalcitrance to both in vitro regeneration and plant genetic improvement. Recalcitrance means that, particular species may have the lowest responsiveness to in vitro regeneration and genetic transformation compared to their counterparts, for example, forage legumes and cereal grain crops (14). This obstacle continues to hamper progress in micropropagation and subsequent attainment of genetic variability, as observed in the most widely cultivated crop species including soybean, common bean, lentil and pigeon pea (Table 1). These crops already serve as important food legumes for human consumption in several subSaharan African countries. Recalcitrant legumes including chickpea, common bean, cowpea and groundnut form part of a daily diet in some countries such as Ethiopia, Kenya and Tanzania (15). Similarly, cowpea has also been indicated to form part of the staple diet for most rural populations in this region, especially in East and West African countries $(14,15)$. Among these, a wide range of grain legume crops and varieties as indicated on Table 1 exist that exhibit different vegetative growths and yield characteristics, accompanied with the greatest potential niche on agriculture in most African countries.

However, crop productivity remains unintensified due to poor quality of seeds, lack of innovative breeding strategies for mass propagation of superior genotypes, lack of effective conservation strategies, frequent and severe droughts, as well as limited adoption of genetically improved varieties. These challenges will persist as long as certain physical seed characteristics (moisture, shape, size, seed damage etc.), which have implications on legume seed germination, regeneration and

Table 1. List of some of the most recalcitrant grain legume crop species found in Sub-Saharan Africa.

\begin{tabular}{ll} 
Species name & Common name \\
\hline Phaseolus vulgaris & Common bean/ dry bean \\
\hline Cicer arietinum L. & Chick pea \\
\hline Vigna unguiculata (L.) Walp & Cow pea \\
\hline Arachis hypogaea & Groundnut \\
\hline Cajanus cajan (L.) Huth & Pigeon pea \\
\hline Pisum sativum & Pea \\
\hline Lens culinaris & Lentil \\
\hline Phaseolus lunatus & Lima bean \\
\hline Phaseolus coccineus & Scarlet runner bean \\
\hline Phaseolus acutifolius & Tepary bean \\
\hline Vigna angularis & Adzuki bean \\
\hline Vigna radiata & Mungo bean \\
\hline Vicia faba & Faba bean \\
\hline Vigna subterranea & Bambara bean \\
\hline Glycine max (L.) Merrill $* *$ & Soy bean \\
\hline Sphenostylis stenocarpa $*$ & African yam bean \\
\hline Mucuna pruriens $*$ & Velvet bean \\
\hline Canavalia ensiformis $*$ & Jack bean \\
\hline
\end{tabular}

Legume species with asterisk show minor $\left(^{*}\right)$ or major $\left(^{* *}\right)$ relevance at international level $(16,17)$.

amenability for genetic improvement remain unachieved. These factors/characteristics will have further implications on the economic value of seeds, production, distribution and conservation of threatened/endangered legume species. Extinction threats are genuine for short-lived legume species also whose seeds cannot undergo long-term storage and with well-maintained long-term seed viability. The long-term viability of legume seeds is critical for maintaining genetic diversity, particularly to enable 
the plants to survive unfavourable biotic and abiotic growth conditions (16-19).

Several key features required for the successful germination and plant establishment under in vitro or in vivo conditions, as well in the field are presented in Table 2. Plant seeds are very critical and central to crop production, human nutrition and food security. The genetic, physiological and physical characteristics define their ability to germinate and rapidly establish uniform seedlings robustly across diverse environmental conditions as echoed above. Seed banks established around the world contain cultivars and land races of crops, but with only a small portion of them falling under wild type species of legumes used as crops. These seed collections have storage conditions favourable for maintaining seed viability (18), but reports indicate that improvements of the conditions are necessary still for the conservation of some specialised recalcitrant legume species. Moreover, the number of neglected and underutilised grain legumes identified based on their domestication, adaptation and utilisation coupled with their general abandonment in research is increasing. Such neglected crops must be improved, explored and their utilisation awareness reawakened to reduce the over-dependency on major staple crops (20). Therefore, the improvement of recalcitrant legumes using plant tissue culture, seed technology, omics technologies and recombinant DNA technology need to be advanced. This should be done to lessen the burden on already existing crops in order to save them from overexploitation and possible extinction of some useful genetic lines.

\section{Somatic Embryogenic Cultures and Production of Synthetic Seeds}

The plant embryo, also known as the seed embryo, is the part of a seed or bud that contains the earliest multicellular stage of a plant's root, stem and leaf. An embryo that develops from sexual recombination of

Table 2. Vital characteristics of good quality seeds, which may differ according to specification of a variety.

\begin{tabular}{l} 
Seed trait \\
Genetic purity \\
\hline Physical quality/ purity (for certification) \\
\hline Shape, size and colour \\
\hline Seed weight \\
\hline Seed viability \\
Seedling vigour \\
Optimum seed moisture content (for storage) \\
Physiological quality \\
Germination rate/ germinability \\
Good market value
\end{tabular}

male and female gametes is termed a zygotic embryo. There is familiarity with zygotic embryo development from seeds, which function as an intermediate stage in the transition between the gamete forming plants to spore producing plants. However, plant embryos are also produced apoptically (without sexual reproduction) from somatic cells in plant tissue culture through a direct or indirect somatic embryogenesis $(1,21)$. This in vitro regeneration system also serves as a prerequisite tool for genetic improvement of horticultural crops, especially through techniques such as recombinant DNA technology, mutagenesis and gene editing methods like the clustered regularly interspaced short palindromic repeats and associated protein 9 (CRISPR-Cas 9). These technologies allow the genetic materials of plants to be altered, added or removed at particular loci in the targeted host plant tissues without the formation of undesirable gene combinations or chimeras (22).

Studies showing high rate of direct somatic embryogenesis using immature cotyledons, leaf tissue explant or indirect embryogenesis from isolated mesophyll protoplasts were reported in legume species such as soybean (Glycine max L.) and barrel medic (Medicago truncatula) (22, 23). In common bean (Phaseolus vulgaris L.), somatic embryogenesis was induced using cytokinin (benzyl adenine) coupled with osmotic stress adaptation instead of supplementing the culture medium with an auxin-cytokinin hormone combination. The study reported pro-embryogenic cell masses derived from apical meristems and cotyledonary zones of zygotic embryos from which secondary somatic embryos were indirectly initiated (24). Somatic embryos (nonzygotic) that are derived from vegetative cells, reproductive tissues or callus were recently reported to be functionally equivalent to zygotic embryos (21, 22).

Moreover, non-zygotic somatic embryos developed from callus cells derived from nutrients enhanced culture media are nutritionally similar to zygotic embryos. Zygotic embryos are typically developed from nutritive seed tissues and connected to the mother cells via a suspensor for further nourishment (21). Callus induced somatic embryos; including embryos from other explant types share the common trait of being able to be manipulated via in vitro culture. Such embryogenic culture systems form the basis for plant improvement using in vitro plant regeneration protocols, coupled with genetic improvement techniques as indicated above $(22,23)$.

Somatic embryogenesis approaches can be used to bypass many barriers associated with sexual reproduction during plant propagation or genetic improvement, including preventing the inherent unwanted consequences of conventional breeding technology. Such unintended effects include undesirable mutations, altered nutritional value, potential health and environmental concerns. Because of these many benefits and commonalities exhibited by different embryo types as well as the various methods available to study and manipulate plants regenerated from them, synthetic seeds emerged as a useful commercial plant propagation tool, which is efficiently served via direct non-zygotic somatic embryogenesis. Synthetic seeds, also known as artificial seeds, are encapsulated somatic embryos, and are produced from other explants such as shoot tips, axillary buds as well as zygotic tissue for deriving secondary embryos (25). Synthetic seeds produced by encapsulation of somatic embryos in a matrix consisting of various concentrations of 
sodium alginate were reported using leaf explants cultured on Murashige and Skoog medium (MS).

Leaf explants cultured on MS medium containing thidiazuron (1.4-5.0 $\mathrm{mg} / \mathrm{l})$, dichlorophenoxy acetic acid $(1.5 \mathrm{mg} / \mathrm{l})$ and benzylaminopurine $(2.0 \mathrm{mg} / \mathrm{l})$ in African violet (Saintpaulia ionantha Wendl.) were reported (26). Synthetic seed technology was also used for germplasm preservation of transgenes and transgenic materials in alfalfa (Medicago sativa). Alfalfa somatic embryos were first transformed using Agrobacterium strain containing DNA construct with a uid reporter gene coding for $\beta$-glucuronidase (GUS) driven by a $35 \mathrm{~S}$ promoter or a tCUP promoter. After desiccation, reported artificial seeds contained about $12-15 \%$ water content, equivalent to the normal seeds and exhibited high degree of viability as well as normal germination upon rehydration (27).

\section{Requirement for Synthetic Seeds}

Reports indicated that recalcitrant legume seeds exhibiting momentary decrease in seed viability and seedling vigour owe their response to the lack of suitable protective mechanisms or processes conferring tolerance to dehydration. The reduction on seed performance results from consequent variability of the responses to stresses, particularly factors imposing severe dehydration on the mature legume seeds. In cucumber (Cucumis sativa) and pea (Pisum sativum), dehydration of seeds induced imbalanced metabolism causing the loss of membrane integrity because of acetaldehyde and ethanol emission from pro-embryo or embryo tissues (28, 29). Meanwhile in Inga (Inga vera) and other legumes, failure to reconstitute damaged microtubular cytoskeleton, short storability and altered cell cycle progression are directly associated with decreased germination and recalcitrance of the seeds (30). The biochemical and physiological processes, followed by morphological changes during seed formation and seed filling were also strongly related to seed longevity/viability. In addition, these processes were also related to the survival rate and vegetative growth of seedlings, which consequently affected yield and quality of seeds produced. Generally, metabolic "switch-off" during seed dormancy and dedifferentiation of cells taking place in orthodox seeds are some of the most crucial mechanisms lacking in recalcitrant seeds, contributing significantly to their desiccation sensitivity (31).

For instance, upon rehydration, orthodox seeds "switch-on" their germination programme, resuming metabolic activities that leads to seedling formation. The expression of thousands of genes form part of this rapid swift from the quiescent state to vegetatively growing seedlings (30). Additionally, when the developmental programme of the individual mature ovules is switched over from embryogenesis to germination, various cell activities change on the level of gene expression, especially when seed embryos are subjected to unfavourable environmental stresses. The germinating seed embryos induce the synthesis of anti-stress proteins to protect themselves and continue with seedling development (32). Gene expression is responsible for the accumulation of dehydrin proteins as a result of drought, chilling, salinity and heat shock proteins as well as chaperones. General-stress-responsive (GSR) genes and heat-shock-proteins (HSP) genes including hspA, groES, groELI, groEL2, dnaJ, htpG, dnak2, clpBI and $h t r A$ are directly related to the molecular mechanisms providing abiotic stress tolerance (33, 34).

Abiotic stress often leads to excessive accumulation of reactive oxygen species (ROS) such as singlet oxygen $\left({ }^{1} \mathrm{O}_{2}\right)$, superoxide radical $\left(\mathrm{O}^{2-}\right)$ and hydrogen peroxide $\left(\mathrm{H}_{2} \mathrm{O}_{2}\right)$. ROS causes oxidative stress damage to the DNA, protein and lipids in which these effects ultimately lead to the failure in seed formation, seed germination and seedling development. As ROS are implicated in the occurrence of various cellular events associated with the inhibition of seed germination, reports indicated that they also promote protection of seed embryos from pathogens and play a critical physiological role in breaking seed dormancy $(23,33,34) . \mathrm{H}_{2} \mathrm{O}_{2}$ for example, is considered a stable form of ROS involved in cellular signalling during germination $(35,36)$. This ROS species was found to safeguard seeds from biotic stress attack by directly affecting pathogens or indirectly inducing programmed cell death (PCD) of the local infected cells. Synseeds are protected from abiotic stress and the subsequent effects of ROS and PCD because they are grown under favourable tissue culture conditions. Therefore, considering the advantageous nature of the evidence presented above, it may be suggested that the production of synthetic seeds via direct or indirect somatic embryogenesis may serve as a proficient alternative to preserve and propagate recalcitrant legume species. Furthermore, the system may provide tight controls on the production and accumulation of ROS, while ensuring seed survival and maintenance of seed viability for longer periods.

\section{Requirement for Synthetic Seeds in Sub-Saharan Africa}

The production of synthetic seeds and consideration of the above-mentioned characteristics will contribute to the use of the produced seeds for germplasm preservation, breeding and the diverse utilisation of recalcitrant seed legumes in subSaharan Africa. This region remains one of the most underdeveloped and highly densely populated regions around the world, yet it is still experiencing low crop yield compared to other regions globally (Fig. 1 A). Sub-Saharan Africa is currently faced with a myriad of economic, health, social and food security crisis, among others. The seed system and its economic value chain are under a massive strain due to inadequate functions resulting from the current narrow germplasm. The lack of organised innovative strategies to deal with adverse conditions (such as drought) and limited adoption of genetically improved cultivars that override internal or external inhibitions, preventing immediate germination also are implicated.

Studies emphasised that, the necessary investments in agriculture, particularly those that 

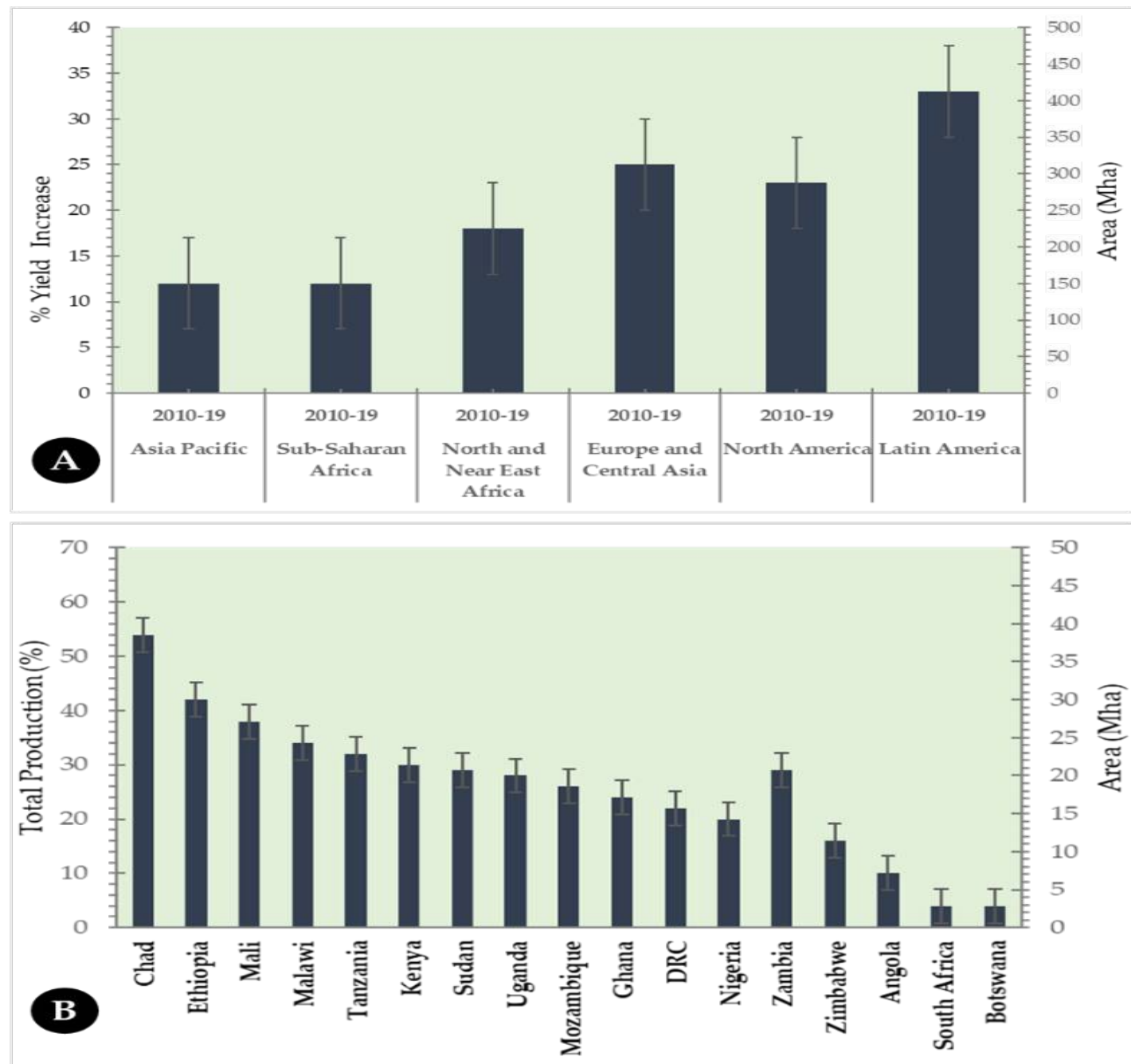

Fig. 1. OECD-FAO estimates of agricultural production based on arable land available for agriculture globally. (A) Total crop yield per region (B) Average gross agricultural value in sub-Saharan Africa from 2010-2016 (46).

would improve the low crop productivity as demonstrated in Fig. $1 \mathrm{~B}$, requires seeds that immediately respond to dormancy-breaking stimuli and germination cues under appropriate conditions (28, 30-32). Even though seed research has evolved, and productivity/ improvement outcomes greatly varies across countries (Fig. 1), renewed interests in the use of agricultural biotechnology applications in sub-Saharan Africa is significant. Thus, synthetic seed formation and maturation suited for efficient rapid multiplication, growth and yield even under stress conditions must be developed to sustain life and maintain adequate food supply for poor rural communities in this region.

\section{Potential Role of Synthetic Seeds in Sub-Saharan African Agriculture}

Generally, seeds are classified into recalcitrant and orthodox seed types based on their ability to germinate following rehydration under optimum growth conditions (37). For orthodox seeds, known as desiccation tolerant, rapid changes in moisture content and metabolism contribute to high seed viability, as well as the high rate of germination upon subsequent receiving of adequate moisture $(32,37)$. Unlike orthodox seeds, legume seed desiccation is directly associated with seed deterioration on both quality and germinability $(14,18,30)$ This phenomenon makes seeds of legume species to be desiccation sensitive and prone to oxidative stress that leads to the loss of seed viability during seed storage (14). However, the use of synthetic seeds produced through plant tissue culture-based somatic embryogenesis as alternative for natural seeds may prolong longevity and ageing challenges faced by recalcitrant species. Recent studies have shown that seed deterioration naturally results from several factors including the genotype, growing environment, harvesting conditions, handling and storing conditions (31, 37-39). Meanwhile, synthetic seeds provide ease of handling, genetic uniformity, low cost of production and direct transplanting without acclimatisation into soil (Fig. 2). Synthetic seeds produced from recalcitrant species would not require special procedures for cryopreservation or specialised conditions to improve amenability for plant genetic improvement (Fig. 2).

This form of new seeds will have the ability to maintain high moisture content, metabolic readiness and ability for rapid germination without suffering desiccation-induced damage, which is frequently observed in natural recalcitrant seeds. The inability of recalcitrant seeds to survive partial 
post-harvest drying, exhibition of short life span and failure to survive in long-term storage in the form of active or baseline seed banks (40), make it impossible for farming systems to rely primarily on biological processes for the production of agroecologically based foods. The use of legume crops is
In addition to the aforementioned properties, the seeds must possess the ability to retain high seed viability after short-term or long-term storage, and maintain high seedling vigour for successful plant establishment even under abiotic stress conditions like drought (Fig. 2). Apart from encapsulated

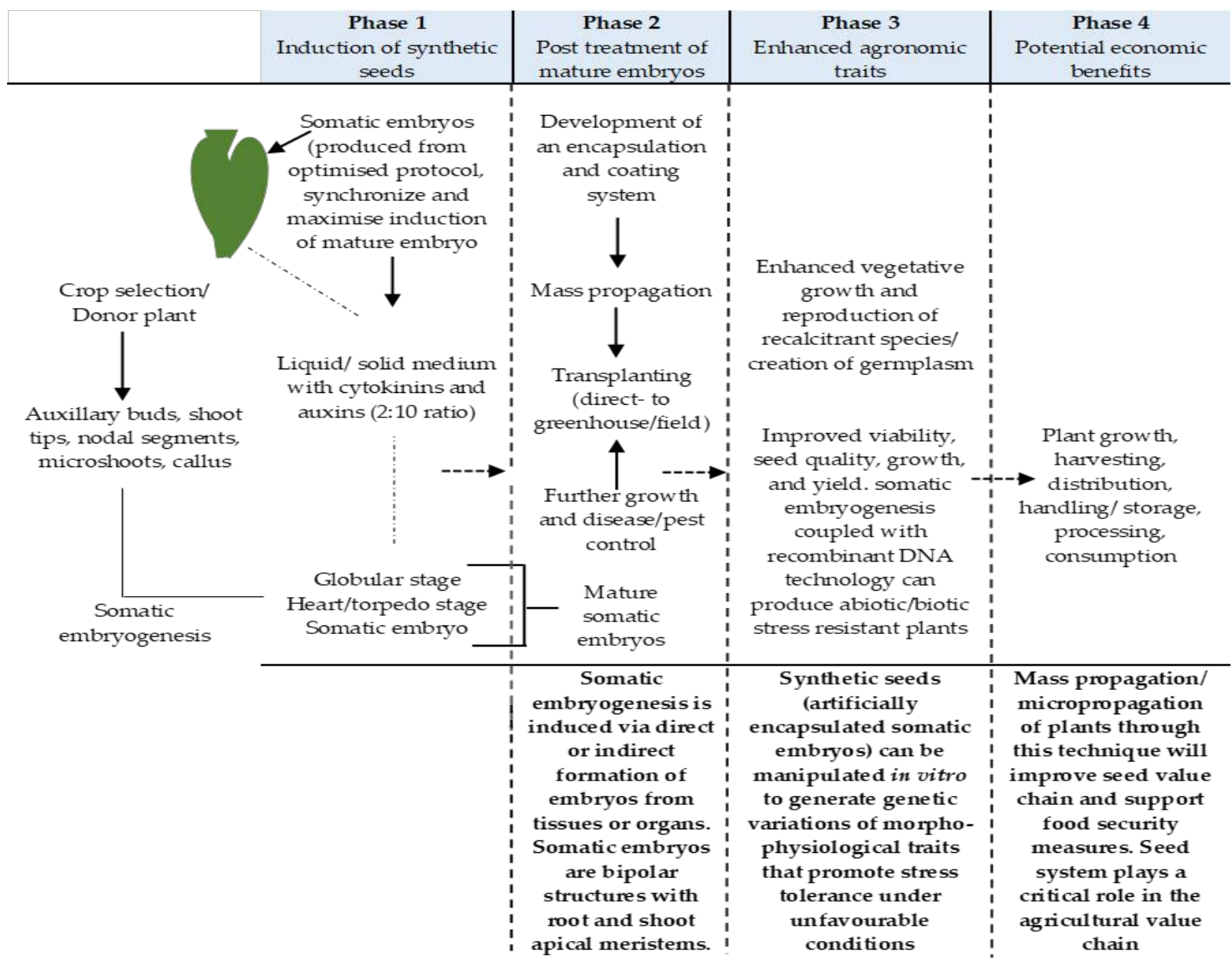

Fig. 2. Schematic representation highlighting stages involved in the commercial production of synthetic seeds and their potential role in agriculture and the economic value chain of seeds in Sub-Saharan Africa.

considered the only alternative to the use of synthetic fertilisers. This may include minimal levels of $\mathrm{CO}_{2}$ /gases emissions, land degradation, tilling and other agricultural practices that are not eco-friendly.

There are seriously reported environmental concerns associated with the unsustainable agricultural practices, primarily including increased occurrence of invasive plant species, resistance to herbicides, impaired water quality and severe health effects, often affecting farmworkers, consumers and the general public (17). It is therefore important to also note that agricultural operations, involving the purchasing of seeds are very expensive for farmers in Africa, a continent with almost no capacity to produce its own genetically improved varieties of legume crops. Therefore, implementation of synthetic seed technology that is not limited to the use of somatic embryos, but includes shoot buds, cell aggregates or any other plant tissue that can be explored for sowing as seeds and regenerate into a mature plant under in vitro or ex vitro conditions must be explored. somatic embryos, other induced somatic embryos can be proliferated for rapid and efficient large-scale in vitro multiplication of elite and desirable plants. The system can be effectively used in a number of micropropagation procedures when mass propagation from recalcitrant legume species, as well as when specific genetic barriers need to be overcome.

The plant tissue culture system, together with the synthetic seed technology could be used to efficiently produce planting materials transplanted into soil in large-scale commercial farming. Crops of other types like bread wheat (Triticum aestivum), corn (Zea mays L.), sorghum (Sorghum bicolor) and rice (Oryza sativa L.) were also reported to have been propagated using in vitro regeneration for mass propagation in commercial farming (41-45). The use of legume crops undoubtedly provides greater opportunities relevant to farmers, consumers, countries' economies and uplifting the socio-economic status of the general population. Governments and their research entities need to give important consideration to address the 
backlog in the use of synthetic seed technology in sub-Saharan African agriculture, preferably those that are farmer-relevant and showing the understanding of the region's demand for food and raw materials.

\section{Application of Plant Tissue Culture and Biotechnology for Agricultural Sustainability in Sub-Saharan Africa}

The barriers to the adoption of plant tissue culture and plant biotechnology-based applications in SubSaharan Africa involves the lack of investments in agricultural technology for plant production, especially for human consumption, animal feed and processing industries. These poor financial and research investments in applications such as the synthetic seed technology lead to massive losses of income, poor GDP growth and the lack of trade returns from agricultural commodity exports. Later these losses have an influence on investments in other sectors, the agricultural sector itself and contributions to food security. As previously indicated, the African continent is marked by very low economic growths, high rates of unemployment, diseases, high mortality rates (especially in children) and food insecurity (3, 4, $15,17,28)$. There are further challenges in this region, beyond developing efficient and profitable agricultural technologies. sub-Saharan Africa desperately needs research to develop comprehensive approaches in dealing with complex problems facing agriculture, including the foreseeable major impacts of climate change. A key challenge for sub-Saharan Africa is the frequent occurrence of extreme temperatures that subsequently lead to both short-term and long-term drought in many parts of the continent.

Given the stated drought conditions, many countries rely heavily on rain-fed agriculture with very low use of irrigation systems (3). Under rainfed agriculture, crops must be provided with sufficient water supply through irrigation, especially when rainfall is not sufficient. An adequate water supply is important for plant growth and productivity, and furthermore, ensures that the effects of climate change and drought stress have very minimum influences on crop yield and grain quality (12). Certain countries in subSaharan Africa have high potential for agriculture, especially the cultivation and production of common bean (Phaseolus vulgaris), cow pea (Vigna unguiculata), chick pea (Cicer arietinum) and pigeon pea (Cajanus cajan), with the additions of Bambara groundnut (Vigna subterranea) and groundnut (Arachis hypogaea). These crops indeed serve as stable legume food crops for the millions of people living in rural communities (17). Thus, the increasing importance of these legume species in the region is evident in their increased exploration for food ingredients, medicinal supplements, biofuel manufacturing and several other products in the textile as well as timber industry. Despite these efforts, the main barriers in the productivity and utilisation of legume crops like cowpea, common bean and pigeon pea is their susceptibility to diseases and pests, in addition to salinity, chilling and drought stress. These forms of abiotic and biotic stresses were also reported in grains such as rice $(44)$, soybean $(11,12)$ and forage crops such as sorghum (41), annual/ perennial ryegrass (Lolium spp.), trefoil (Lotus corniculatus), medics (Medicago spp.) and clover (Trifolium spp.) (47).

All these reported crops had a greater impact on agriculture globally in a number of unique ways, particularly when plant propagation by seeds or cuttings was coupled with in vitro tissue culture and biotechnology. For this reason, mass propagation of these crop plants via synthetic seeds can be used not for clonal multiplication purposes only, but as a tool for plant breeders to enhance genetic improvement and then simplify mechanisms to regenerate mature plants from recalcitrant legume species. If plant tissue culture is widely used in sub-Saharan Africa, mass propagation under industrialised conditions at low cost per unit would allow clonal propagation that replaces traditional use of seeds for propagation, replacing production of hybrid plants through hand-pollination and then serving as a reliable source of preferred biochemical, epigenetic or genetic variations (48). Since in vitro regeneration serves as one of the important standard propagation systems in common horticultural crops, techniques involved in these systems still need to be optimised for efficient and increased frequency of mass propagation or genetic recombination of desirable traits. The biotechnological development of clonal propagation, pathogen-free plants, drought tolerant plants, fertile and nutritionally enhanced cultivars, year-round nursery production and germplasm preservation are fundamental prerequisites for the sub-Saharan African economy and the population's livelihoods.

\section{Conclusion}

The mass production of important leguminous crops that have proved recalcitrant for many generations could be achieved through the production of synthetic seeds via somatic embryogenesis. This demand for micropropagated plant materials is high in sub-Saharan Africa where the need for economic emancipation, nutrition and health-promoting solutions is continuously expanding due to the increase in population and climate change. However, lack of political stability, implementation of progressive agricultural policies and biotechnological solutions are a reflection of the ineffective seed value chain that do not translate into better economic returns despite the large diversity of germplasm that this region contains. Therefore, tools such as synthetic seed technology have the potential to increase crop plant propagation rates, improve crop market value, make propagation of recalcitrant crops possible and play a critical role in germplasm preservation. Furthermore, this seed system will facilitate the distribution of important and commercially viable legume plant materials, 
assisting this region in meeting its food security obligation.

\section{Acknowledgements}

The Author would like to thank the Department of Research Administration and Development, University of Limpopo, Republic of South Africa for funding the article publication charge.

\section{Conflict of interests}

Authors do not have any conflict of interests to declare.

\section{References}

1. Rihan HZ, Kareen F, El-Mahrouk ME, Fuller MP. Artificial seeds (Principle, aspects and applications). Agronomy. 2017;17:71. https://doi.org/10.3390/agronomy7040071

2. Bhatia S. Application of plant biotechnology. In Bhatia S, Sharma K, Dahiya R, Bera T, (editors). Modern Applications of Plant Biotechnology in Pharmaceutical Sciences. New York: Academic Press; $2015 . \quad$ pp. 157-207. https://doi.org/10.1016/B978-0-12-802221-4.00005-4

3. Shimeles A, Verdier-Chouchane A, Boly A. Introduction: Understanding the challenges of the agricultural sector in SubSaharan Africa. In: Shimeles A, Verdier-Chouchene A, Boly A, (editors). Building a Resilient and Sustainable Agriculture in Sub-Saharan Africa. Cham: Palgrave Macmillan; 2013. pp. 112. https://doi.org/10.1007/978-3-319-76222-7_1

4. Gashu D, Demment MW, Stoecket BJ. Challenges and opportunities to the African agriculture and food systems. African Journal of Food, Agriculture, Nutrition and Development. https://doi.org/10.18697/ajfand.84.BLFB2000

5. Shi Z, Yao Y, Zhu Y, Ren G. Nutritional composition and antioxidant activity of twenty mung bean cultivars in China. Crop Journal. 2016;4(5):398-406. https://doi.org/10.1016/j.cj.2016.06.011

6. Jarpa-Parra M. Lentil protein: A review of functional properties and food application. An overview of lentil protein functionality. International Journal of Food Science and Technology. https://doi.org/10.1111/ijfs.13685

7. Solomon SG, Okomodu VT, Oda SO. Nutritional value of toasted pigeon pea, Cajanus cajan seed and its utilisation in the diet of Clarias gariepinus (Burcell, 1822) fingerlings. Aquaculture Reports. https://doi.org/10.1016/jaqrep.2017.05.005

2017;7:34-39

8. Celmeli T, Sari H, Adak HCDSA,Eker T. The nutritional content of common bean (Phaseolus vulgaris L.) landraces in comparison to modern varieties. Agronomy. 2018;8:166. https://doi.org/10.3390/agronomy8090166

9. Etemadi F, Hashemic M, Barker AV, Zandvakili OR, Liu X. Agronomy, nutritional value and medical application of faba bean (Vicia faba L.). Horticultural Plant Journal 2019;5(4):17082. https://doi.org/10.1016/j.hpj.2019.04.004

10. Lu ZK, He JF, Zhang YC, Ding DJ. Composition, phytochemical properties of pea protein and its application in functional foods. Critical Reviews in Food Sciences and Nutrition. 2019;113. https://doi.org/10.1080/10408398.2019.1651248

11. Mangena P. Effect of hormonal seed priming on germination, growth, yield and biomass allocation in soybean grown under induced drought stress. Indian Journal of Agricultural Research. 2020;1-7. https://doi.org/10.18805/IJARe.A-441

12. Mangena P. In vivo and in vitro application of colchicine on germination and shoot proliferation in soybean [Glycine max
(L.) Merr.] Asian Journal of Crop Sciences. 2020;12:34-42. https://doi.org/10.3923/ajcs.2020.34.42

13. Imran M, Nadeem M. Triacylglycerol composition, physicochemical characteristics and oxidative stability of interestified canola oil and fully hydrogenated cottonseed oil blends. Lipids in Health and Diseases. 2015;14:138. https://doi.org/10.1186/s12944-015-0140-0

14. Hnatuszko-Konka K, Kowalczyk T, Gerszberg A, WiktorekSmagur A, Kononowicz A. Phaseolus vulgaris- Recalcitrant potential. Biotechnology Advances. 2014;34:1205-15. https://doi.org/10.1016/j.biotechadv.2014.06.001

15. Van Loon MP, Deng N, Grassini P, Edreira JIR, Wolde-meskel E, Baijukya F, Marrou H, van Ittersum MK. Prospect for increasing grain legume crop production in East Africa European Journal of Agronomy. 2018;101:140-48. https://doi.org/10.1016/j.eja.2018.09.004

16. Finch-Savage WE, Bassel GW. Seed vigour and crop establishment: Extending performance beyond adaptation Journal of Experimental Botany. 2016;67(3):567-91. https://doi.org/10.1093/jxb/erv490

17. Snapp S, Rahmanian M,Batello C. Pulse crops for sustainable farms in Sub-Saharan Africa. Rome: FAO; 2018. pp. 1-60. https//fao.org/3/18300EN/i8300en.pdf

18. Molnar AV, Sonkoly J, Lovas-Kiss A, Fekete R, Takacs A Somlyay L, Terok P. Seed of the threatened annual legume, Astragalus comtortuplicatus can survive 130 years of dry storage. Preslia. 2015;87:319-28.

19. Mangena P, Mokwala PW. The influence of seed viability on the germination and in vitro multiple shoot regeneration of soybean (Glycine $\max$ L.). Agriculture. 2019;9(2):35. https://doi.org/10.3390/agriculture9020035

20. Popoola J, Ojuederies O, Omonhinmin C, Adegbite A. Neglected and underutilised legume crops: Importance and future prospects. In: Shah F, Khan Z, Iqbal A, Turan M,Olgun M (editors). Recent Advances in Grain Crops Research. United Kingdom, London: IntechOpen;2019; pp. 1-23. https://doi.org/10.5772/intechopen.87069

21. Gray DJ. Propagation from non-meristematic tissues: Nonzygotic embryogenesis. In Trigiano RN, GrayDJ (editors). Plant Development and Biotechnology. New York: CRC Press; 2005. pp. 187-200.

22. Raza G, Singh MB, Bhalla PL. Somatic embryogenesis and plant regeneration from commercial soybean cultivars. Plants. 2020; 9(1):38. https://doi.org/10.3390/plants9010038

23. Rose RJ. Somatic embryogenesis in the Medicago truncatula model: Cellular and molecular mechanisms. Frontiers in Plant Sciences 2019;10:267. https://doi.org/10.3389/fpls.2019.00267

24. Cabrera-Ponce JL, Gonzalez-Gomez I, Leon-Ramirez C Sanchez-Arrequin JA,yGarfias, AEJ. Somatic embryogenesis in common bean Phaseolus vulgaris L. In Loyola-Vergas V, OchoaAlejo N (editors). Plant Cell Culture Protocols- Methods in Molecular Biology. New York: Humana Press; 2018. pp. 189203. https://doi.org/10.1007/978-1-4939-85944_12

25. Ravi D, Anand P. Production and application of artificial seeds: A review. International Research Journal of Biological Sciences. 2012; 1(5):74-78.

26. Taha RM, Daud N, Hasbullah NA, Awal A. Somatic embryogenesis and production of artificial seeds in Saintpaulia ionantha Wendl. Acta Hort. 2009;829:331-36. https://doi.org/10.17660/ActaHortic.2009.829.51

27. Liu W, Liang Z, Wang X, Sibbald S, Hunter D, Tian L. Presentation and faithful expression of transgene via artificial seeds in alfalfa. PLoS One. 2013;8(15):e56699. https://doi.org/10.1371/journal.pone.0056699

28. Leprince O, Harren FJM, Buitink J, Alberda M, Hoekstra FA. Metabolic dysfunction and unabated respiration precede the loss of membrane integrity during dehydration of germinating radicles. Plant Physiology. 2000;122:597-608. https://doi.org/10.1104/pp.122.2.587

29. Awosanmi FE, Ajayi SA,Baffoe EE. Influence of seed moisture content on short term storage of cowpea (Vigna unguiculata (L.) Walp) seeds. Agriculturae Conspectus Scientificus. 2020;85(1):37-42. 
30. Faria JMR. Desiccation tolerance and sensitivity in Medicago truncatula and Inga vera seeds [PhD Thesis]. Netherlands: Wageningen University; 2006.

31. Berjak P, Pammenter NW. Implications of the lack of desiccation tolerance in recalcitrant seeds. Frontiers in Plant Sciences. 2013;478:1-9. https://doi.org/10.3389/fpls.2013.00478

32. AzarkovichMI. Stress-induced proteins in recalcitrant seeds during deep dormancy and early germination. In: Shanker A Shanker C (editors). Biotic and Biotic Stress in Plants- Recent Advances and Future Perspectives. United Kingdom, London: IntechOpen; 2016. pp. 317-35. https://doi.org/10.5772/61958

33. Zhang L, Zhao HK, Dong QL, Zhang YY, Wang YM, Li HY, Xing GJ, Li QY, Dong YS. Genome-wide analysis and expression profiling under heat and drought treatments of HSP70 gene family in soybean (Glycine max L.). Frontiers in Plant Sciences. 2015:6:773. https://doi.org/10.3389/fpls.2015.00773

34. Liu L, Li J, Zhu Y, Jones A, Rose RJ, Song Y. Heat stress in legume seed setting: Effects, causes, and future prospects. Frontiers in Plant Sciences. 2019;10:938. https://doi.org/10.3389/fpls.2019.00938

35. Bailly C. The signalling role of ROS in the regulation of seed germination and dormancy. Biochemistry Journal. 2019; 476(20):3019-32. https://doi.org/10.1042/BCJ20190159

36. Petrov VD, Van Breusegem F. Hydrogen-peroxide- a central hub for information flow in plant cells. AoB PLANTS. 2012; 014. https://doi.org/10.1093/aobpla/pls014

37. Kumar SPJ, Prasad SR, Banerjee R, Thammineni C. Seed birth to death: dual functions of reactive oxygen species in seed physiology. Annals of Botany. 2015;116:663-68. https://doi.org/ 10.1093/aob/mcv098

38. BarbedoCJ. A new approach towards the so-called recalcitrant seeds. Journal of Seed Sciences. 2018;40(3):221-36. https://doi.org/10.1590/2317-1545v40m3207201

39. Bereke T. Biology of seed development and germination physiology. Advances in Plants and Agricultural Research. 2018;8(4):336-46. https://doi.org/10.15406/apar.2018.08

40. Obroucheva N, Sinkevich I,Lityagina S. Physiological aspects of seed recalcitrance: A case study on the tree Aesculus hippocastanum. Tree Physiology. 2016;36(9):1127-50. https://doi.org/10.1093/treephys/tpw037

41. Baskaran P, Jayabalan N. In vitro plant regeneration and mass propagation system for Sorghum bicolor- A valuable major cereal crop. Journal of Agricultural Technology. 2005;345-64.
42. Yasmin S, Khan IA, Khatri A, Seema N, Nizamani GS, Arain MA. In vitro plant regeneration in bread wheat (Triticum aestivum L.). Pakistan Journal of Botany. 2009;41(6):2869-76.

43. Vorpsi V, Rama P,Hodaj B. The use of corn starch on in vitro propagation of plum. Albanian Journal of Agricultural Sciences. 2012; 11:169-172.

44. Islam $\mathrm{M}$, Roly $\mathrm{ZY}$, Lee $\mathrm{Y}$, Khalekuzzaman $\mathrm{MD}$. In vitro propagation and genetic transformation system using immature embryos in elite rice (Oryza sativa L.) cultivars. Plant Breeding and Biotechnology. 2014;2(1):88-96 https://doi.org/10.9787/PBB.2014.2.1.088

45. DregerM, Mol R, Deja A, Raj E, Mankowska G, Wielgus K. Improved plant regeneration in callus cultures of Sorghum bicolor (L.) Moench. In Vitro Cellular and Developmental Biology - Plant. 2019;55:190-98. https://doi.org/10.1007/s11627019-09963-9

46. Organisation for Economic Co-operation and Development (OECD) and the Food and Agriculture Organisation (FAO) of the United Nations. OECD-FAO Agricultural Outlook 2019-2018. Rome: $\quad$ OECD-FAO; $2019 . \quad$ pp. $1-140$ https://doi.org/10.1787/agr_outlook-2019-en

47. Capstuff NM, Miller AJ. Improving the yield and nutritional quality of forage crops. Frontiers in Plant Science. 2018;9:535. https://doi.org/10.3389/fpls.2018.00535

48. Hartmann HT, KesterDE, Davies FT, Geneve RL. Hartmann and Kerster's Plant Propagation Principles and Practices $8^{\text {th }}$ edition. New York: Pearson Education Limited; 2014. pp. 670-724.

\section{Additional information}

Peer review information: Plant Science Today thanks Sectional Editor and the other anonymous reviewers for their contribution to the peer review of this work.

Reprints and permissions information is available at

https://horizonepublishing.com/journals/index.php/PST/open_access_policy

Publisher's Note: Horizon e-Publishing Group remains neutral with regard to jurisdictional claims in published maps and institutional affiliations.

To cite this article: Mangena P. Synthetic seeds and their role in agriculture: status and progress in sub-Saharan Africa. Plant Science Today. 2021;8(3):482-490. https://doi.org/10.14719/pst.2021.8.3.1116

Plant Science Today, published by Horizon e-Publishing Group, is covered by Scopus, Web of Science, BIOSIS Previews, Clarivate Analytics, etc. See https://horizonepublishing.com/journals/index.php/PST/indexing_abstracting 